\title{
Alienation and Return: School Cultural Construction With Characteristics*
}

\author{
Long An-bao \\ Southwest University, Chongqing, China \\ Guiyang No.14 High School, Guiyang, China
}

\author{
Cui You-xing, Li Sen \\ Southwest University, Chongqing, China
}

\begin{abstract}
The school culture with characteristics refers to the culture that is either "school-based" or "for the school", which highlights the personality and characteristics of the school, and it is formed on the foundation of the school development with a long history. The school culture with characteristics helps to cultivate innovative talents, enhence the diversification development of the school, and deepen the reform of basic education. In the process of the school cultural construction with characteristics, there appeared a series of problems which indicated the symbols of alienation slogans with utilitarian value-orientation, adult logic overstepping the philosophy of the children, and the external administrative dominant inhibition to the inner motivation. Returning to the nature of the school culture construction, we need to clarify the motivation, identify the subjects, expand the contents, and optimize the path to success.
\end{abstract}

Keywords: school culture with characteristics, cultivation of innovative talents, adult logic, philosophy for children

\section{Introduction}

Planning Outline of National Long-Term Education Reform and Development (2010-2020, China) put forward that "We are setting up measures to improve the quality as the core concept of education development, paying attention to the education connotation development, encouraging to run schools with characteristics, and producing qualified education with high level” (The State Council of People's Republic of China, 2010). The school culture with characteristics is the core culture, which is quite different from others, and it enjoys the unique symbol of its own. School culture has three remarkable characteristics. First, it is historical. It is based on the development history of the school which has a profound historic implication. The historic implication of the school culture is the foundation and durable motive-power source. Second, it is different. The famous American anthropologist Ruth Benedict said, "Culture is a kind of way of thinking and action through activities demonstrated by a nation, and it is a way that makes the nation different from any others" (Victor, 1988, p. 5). Therefore, the school culture with characteristics focuses on "unique characteristics", it means "searching for your own words" (Yang, 2013). Third, it is educational. Culture, at a deeper level, is the basic assumption and belief which is recognized and shared by the members of the organization, subconsciously affects the following

\footnotetext{
* The annual basic scientific research for the Special Fund Projects of “Central Universities”, Southwest University, 2014. (Project No.: SWU1409344).

Long An-bao, Ph.D. candidate, Faculty of Education, Southwest University; Guiyang No.14 High School.

Cui You-xing, Ph.D. candidate, Faculty of Education, Southwest University.

Li Sen, Ph.D., professor, Faculty of Education, Southwest University.
} 
function of achieving cultural people, realizing the aim of educating people. The soul of the school culture with characteristics is aimed at educating people by cultural invasion and nourishing to enable teachers and students to have diversified development paths and generate the spiritual meaning.

\section{Alienation in the School Cultural Construction With Characteristics}

In the reform of basic education, the majority of primary and secondary schools have vigorously carried out the plan of school cultural construction with characteristics, and a large number of distinctive cultural campuses with characteristics came into being and achieved good results. However, in practice, there are some problems to be solved due to promoting "too excessively and too fast" and many other reasons.

\section{The Utilitarian Value-Orientation Deviated From Ontology}

The essence of culture is of human nature and for human nature. People and culture have a close relationship. Neither discussing the culture without people nor talking about people apart from the culture is called the alienation of losing the root. Ernst (2004) said in An Essay on Man:

For understanding the richness and variety of the forms of human cultural life, the reason is not a suffient name. However, all these cultural forms are symbolic form. Therefore, we should define people as the symbolic animals to replace man defined as rational animals. Only in this way can we specify unique people, also can we understand the new road which is open to the humankind — the road leading to the culture. (p. 37)

Culture is a collection of significant symbols. Only through the culture can we understand the uniqueness, diversity, and creativity of people. Culture came into being with the original occurrence of human beings. It is created by human beings and embodied the essential attribute of human beings. Therefore, the ontological value of the school cultural construction with characteristics is based on the school, to realize the harmonious development of teachers and students. However, in the process of school cultural construction with characteristics, a large number of slogans prevalently highlight the utilitarian value-orientation, such as "Building the campus culture", "Casting a school with characteristics", "Making the campus cultural brand", "The construction project of the campus with characteristic culture", and so on. To a certain extent, these slogans can effectively express the determination and courage of the campus cultural builders. However, after being thought out carefully, it implies the urgent mentality for instant success in the school cultural construction, linear engineering thinking, ignoring the relationship between the human and the culture, and the way of jumping forward with its ontological value.

\section{Adult Logic Assuming on the Philosophy for Children}

The primary purpose of the school cultural construction with characteristics is to promote the development of the school, both its diversification and individuation, just like Ernest Hemmingway's famous saying, "Searching for your own words", while the ultimate goal is to realize the development of teachers and students positively, healthily, happily, and harmoniously. However, in practice, from the perspective of adults, the phenomena of school cultural construction with characteristics can be found everywhere. The fact that the adult logic is assuming on the philosophy for children has made the school cultural construction with characteristics go away from the culture itself, and deviate from the purposes of the school cultural construction with characteristics. In the school cultural construction with characteristics, the actions mainly manifest adults' thinking way and the retreat of the philosophy for children. On one hand, in the process of planning and construction of the school culture with characteristics, decision-makers just concern about the development of 
the school and highlight the school character, but show less or no considerations to the position of the students and their development needs. On the other hand, a large number of school cultures with characteristics reflect that the philosophy for children is ruthlessly submerged. For example, in the construction of scholarly cultural campus, it is refined by using of modern technology. A large number of works of calligraphy are copied or carved in the walls in every corner of the school, especially various kinds of cursive works and seal script works, which are quite popular. Just carving simple replication can emit the scholarly atmosphere in the campus? How many people can be familiar with such varieties of cursive and seal script works? Do not even talk about the primary students who are still in the literacy stage and to what extent can they enjoy the elegant culture in such cultural circumstances?

\section{Administrative Dominant Inhibition to the Inner Motivation}

In a certain sense, the school culture with characteristics is not constructed artificially, on the contrary, it can only naturally be formed through gradual accumulation in the process of the development of the school with long history and formed concisely at last. It is neither given exteriorly by others, nor self-proclaimed, but an intrinsic expression and the highlight of the inner connotation. The formation of the school culture with characteristics is a kind of self-conscious demonstration and a continuous process of development. However, in practice, the school cultural construction was described as a "government behavior", or a sign of "brand", "project", and so on, especially the education assessments and a lot of acceptance work with various multitude of names. The school culture with characteristics will be mechanically separated into different modules through quantitative indicators, and it will lose the cultural inherent attribute and the educational value. Although the school cultural construction with characteristics needs the support from external power, especially the improvement pushed by the government and its more rational actions. However, too much administrative intervention and dominantly executive guidance will make the school lose its subjectivity in cultural construction with chatacteristics, damage the task, or achieve the alienation as a series of policy execution and the index of the school cultural construction with characteristics. Furthermore, declining the subjectivity characteristics of school cultural construction will lead to the lack of intrinsic motivation, and in practice, the dynamic school cultural construction with characteristics will often be vanished, disappearing as a flash in the pan.

\section{The Ontological Regression of the School Cultural Construction With Characteristics}

School culture includes the school material culture and spiritual culture. "The school culture is reflected as the institutional culture of the school curriculum, the formation and interaction of teacher culture, student culture, and environmental culture to form the school's unique culture” (Zhong, 2003). Today, there exist three distinct forms of the school cultures, namely, the examination-oriented school culture, the development-oriented school culture, and the mixed type of school culture. The development of school personality determines the personality development of the students each. The ontological and authentic value of the school cultural construction with characteristics highlights the characteristics itself, and emphasizes the model of running schools with characteristics.

We are seeking the ontological value of culture and returning the school cultural construction with characteristics, we need to follow the cultural nature, which is based on school practice and the harmonious 
development of teachers and students as the purpose.

A large number of experienced, first-class teachers are needed in the school cultural construction with characteristics, and all the teachers (Fang, 2006) "dare to explore the new ideas that was still not invented, that is the spirit of innovation; dare to hunt the savage frontier, that is the spirit of opening up the territory”. We should advance the overall school cultural construction with characteristics by clarifying the motivations, identifying the subjects, expanding the contents, and optimizing the path.

\section{Clarifying the Motivation}

The school culture with characteristics is also popularly called the special culture of the school with personality or individuality. In order to understand the real conception and have a deep recognition to the culture with characteristics, we need to clarify the motivations. Professor Ye Lan pointed out that:

The formation of the school cultural individuality depends on the school leadership who grasp and discriminate the degree of cultural traditions which have been formed in the development history of their own school, depends on the leadership who grasp the contemporary social changes and the great culture mission of the school, depends on the leadership who grasp the current state of the school teachers and students and the cultural characteristics which were formed in different backgrounds of life, and besides on this basis, the cultural pursuit of reflecting and adapting to the school running concept should be refined and formed. (Ye, 2006, p. 390)

The school cultural construction with characteristics has three stratifications of reasons. The first stratification is the historical cultural tradition of the school. Cultural tradition is the "immortal soul of the nation”, it is something as if:

It were an entity without shape, and it could not be touched. It were existing at no place, but it were existing everywhere. It were not only in all traditional culture, but also in all real culture with reality, as well as in our souls. (Pang, 1993)

Knowing the traditional cultural contributions of the school can help explore the high quality seeds of the school cultural construction with characteristics, to lay a solid cornerstone of the school development with characteristics. Second, it is the development mission of the times and core values of the society. Different times give different missions to the people (the subject), and different societies show different core values. In the era of knowledge economy, innovation and change is the eternal theme. The concept of the socialism core value emphasizes justice, fairness, ethics, integrity, and moral. Therefore, the school cultural construction with characteristics should not only fully embody the characteristics of the times and assume the mission with courage of the times, but also reflect and highlight the core values of socialism. The third stratification is the current practice of the school. It is the reality of the school that is the premise of the school cultural construction with characteristics. The geographical spatial characteristics of the school, the state of the teachers and students, and the cultural traits with different background of life control the formation of the school culture with characteristics. Therefore, the motivation of system integration to school cultural construction with characteristics is the must-route for current school cultural construction with characteristics to escape from the complex difficulties, to run beyond the history and reality, and to realize the transformation and reconstruction of school culture.

\section{Identifying the Subjects}

Digesting the dominant executives and too much interventions from the government and promoting the intrinsic dynamic power of school cultural construction with characteristics need to break the single subjective 
view and establish the multi-subjective view. Hu and Gong (2008) pointed out that "including the headmaster of the school, teachers, students, staff, experts, parents, and community service workers who indirectly participate in the school cultural construction, all play important roles and assume corresponding responsibilities, and jointly form an entity of community construction”.

First of all, the principal is the leader and decision-maker in the process of school cultural construction with characteristics. In the course of school cultural construction with characteristics, the principal should have the strategic consciousness for the development of the school cultural characteristics, and establish a concept of "revitalizing school by culture" and "strengthening school by culture". At the same time, the principal should also have personalized educational thought and scientific arts of leadership to lead the school cultural construction with characteristics. Second, teachers and students are the main subjects in the school cultural construction with characteristics. They need to give full play to their creativity. We should let them participate in the planning and design of the school cultural construction with characteristics, coagulate the school cultural value, and create the material environment with school cultural characteristics. On one hand, teachers are the main practitioners, users, and creators of the school culture with characteristics, they spread and propagate the school culture with characteristics in their teaching activities and daily behaviors among their students. On the other hand, students participating in the school cultural construction with characteristics not only helps to break through that the adult logic is assuming on the philosophy for children, but also contributes to the formation of the new model culture of the students, to fully develop the potential of the students and promote diversified development. Third, parents, alumni, and community service workers are important participants in the school cultural construction with characteristics. On one hand, they are the eyewitnesses of the historical development of the school, and they are organic parts of school culture; on the other hand, in the school cultural construction with characteristics, they are willing to and also have the ability to provide varieties of resources, such as intelligence support, financial support, and so on.

\section{Expanding the Contents}

The school cultural construction with characteristics is to highlight the personality, the culture of the school, and the uniqueness and superiority. Its focus is not on "big" and "complete", but on "special" and "fine". Overall, the multi-contents of the school cultural construction with characteristics include the curriculum culture, teaching culture, teacher culture, student culture, and organization and management culture of the school. Curriculum culture is mainly embodied as the school-based curriculum development with school characteristics. The school-based curriculum not only has knowledge value, but also contains the idea of running school and the view of educational value, and has rich educational value. Zhang (2008) said, "The value, spirit, and meaning contained in the curriculum are not directly inculcated to the students, but they are generated by the way of forming consensus in the process of consultation and interaction between teachers and students". Teaching culture focuses on classroom teaching reform as the core, and it is in classroom teaching that teachers and students can realise "Teaching is learning” through dialogues, communications, cooperations, and other ways. Generally, teaching culture includes the transformation of teaching methods, construction of new teaching modes, innovation of the teaching process, and so on. Teacher culture is teacher-centered, formed by daily communication practices, and it is a kind of culture with integration, development, and significance. Generally, it embodies by the learning community of teachers, teaching and research groups, the school-based teaching research, and so on. Student culture is an important part of the school culture with characteristics, and 
it reflects the survival status and mental state of the student groups. Student culture in general appears among the peer groups, interest groups, the students' daily learning and communication activities. Organizational culture is an important mechanism for promoting the school cultural construction with characteristics, it generally includes the reasonable setting of the school organization, the system design, the management style of the leadership, the collaborative work among the staff, and so on.

\section{Optimizing the Path}

The path of school cultural construction with characteristics mainly formed by the organic parts of "concentrating concept, materializing shape, internalization generating, and externalization displaying” (Ai, 2005; Sun, 2012). Concentrated concept is the prerequisite for the formation of the school culture with characteristics. The concept refining is based on the development of the school history, the current practice, and the characteristics of times.

A culture creates an idea, and the idea leads to the development of the culture. The idea has the functions of guidance, cohesion, and incentive function. Concentrated concept is the premise of the formation of the core values of school culture with characteristics. The concentrating of an idea is based on the overall comprehensive analysis of the history of the school development, the present practice, and the characteristics of the times. For example, Guiyang No.14 High School, which is lying on the Nanming River and staying at the foot of a mountain with trees-lined and grass growing here and there, was named "green garden-like school" because of its beautiful environment. The school was founded in 1958, with the pioneers' early contribution and the unremitting efforts of hard woking by its staff and students for generations. Continuing to adhere to the educational philosophy of "people-oriented first, harmonious development, establishing the school with noble ethics, revitalizing the school based on scientific research"; persisting in the educational idea of "imparting knowledge and educating people, educating people by management, educating people by service, and educating people by environment"; refining the school motto of "pursuing the truth, the kindness, the perfect, and the healthy", forming the school spirit of "faithfulness, diligence, solidarity, and competition"; keeping on the school moral ethics of "noble ethic as model, cultivating the young silently"; forming the teaching attitude of "preciseness, innovation, devotion, and contribution"; constructing the learning style of "respecting others, observing the rules, curiousness for science and reflection"; and upholding the concept of the new curriculum reform, the professional development of teachers, and the development of all the students, the school has now become a "green garden-like school" with the characteristics of "beautiful campus, well learning atmosphere, high educational quality, strengthened scientific research, and unique management” in Guiyang, a cool city in China.

Guiyang No.14 High School, through the forms of materialized shaping, spatial expression, internalization generated, and externalization display, has highlighted the campus culture with characteristics of its own. Materialized shaping is to create the school culture with characteristics from the aspect of physical environment, it uses the direct way of perception, vivid expression of ideas, and cultural value of the school; spatial expression is displaying the teachers and students' scientific and technical innovations and arts, which are created in the integrated practice activities by making full use of the walls, corridors, any cormer in the campus, or unused space, for instance, the electronic robots made in the comprehensive practical activities are special and successful. In order to create the special campus culture with characteristics, all kinds of the creative works reflecting different aspects of school cultural construction with characteristics produced by the students and 
staff of the school can be viewed in the school yard, from the spatial layout and the designing dimensions of the contents, from the school badge, school song, uniforms, design of the school gate to the layout of the teaching buildings, as well as the construction of the cultural corridors and making full use of the cultural plaza, etc.. While walking into the school, you will see the famous maxims, calligraphy paintings, inspirational words, funny events of alumni, and the directory of the school history here and there. Internalization is the main path of the generated characteristics of the school cultural construction, which is a key link to realize cultural education, even more to protrude the school prominently with its developing connotation of "strengthening the inner body with high cultural quality, and setting up wonderfully characteristic image to the society outside”. It needs a long-term process, and it is a complex process of gradually self-identity and internalizing the value of school culture with charateristics while teachers and students are enjoying the perception of understanding the idea of the school cultural value in the infiltration of the school culture. The generated internalization of the idea of the school cultural value can generally be expanded through the organization of seminars, classroom teaching permeation, daily communications, etc.. For example, teachers and students can be organized to have seminars to implement special issues around the concept of the school cultural value, to have school sports meeting, to have topical speech, and to have reading competitions of China's traditional-culture classics and singing contests. Teachers should consciously tell about the development of the school history, anecdotes, and the development visions in their daily teaching; students would be affected through the student groups, especially influenced by various informal peer groups and promoted to have the awareness of cognition, identification, and internalization to the school cultural concept with characteristics. Externalization display is the overall expression of the school culture with characteristics, it promotes the influence power of the school by appearing and publicizing the school culture with characteristics. Externalization display mainly includes three aspects: 1 . The school image as a whole and the level of running should be advanced, and the influence of the school should be further expanded and enlarged; 2. All the teachers should be tireless in teaching, have highly full of vigor, courage, and spirit, and enjoy the teachers' professional happiness; and 3. All the students should keep a state with high aggressive spirit, be diligent, enjoy their school learning and "learning by doing", learn to coorprate harmoniously with others, and act good behaviors every day.

\section{Conclusion}

The school cultural construction with characteristics is an essential issue for development. It generally contains curriculum culture, teaching culture, teacher culture, student culture, and organizational culture. We have to solve the problems of utilitarian value-orientation, adult logic overstepping the philosophy of children, the external administrative dominant inhibition to the inner motivation, and so on. We should return to the nature of the school culture with characteristics to the students and staff. We need to clarify the motivation, identify the subjects, expand the contents, and optimize the path to success. First, moral education, healthy education, and safety education are the three most important. We must help the students learn to be, learn to live, learn to study, and learn to share. Second, we need to analyze the development of school culture with characteristics, and make clear the advantages or disadvantages before we take decisive measures to choose the individualized development path. Third, we must instruct the classroom with vitality by keeping praising culture, exploring culture, and cooperating culture. Fourth, in order to build a harmonious teaching-research culture, we should create more famous teachers' working studios and establish the ascension culture which is conducive to promote teachers' professional development. 


\section{References}

Ai, K. R. (2005). Concentrating school running idea to strengthen school running with characteristics. Journal of Chengdu Institute of Education, 7, 59-61.

Ernst, K. (2004). An essay on man. (Y. Gan, Trans.). Shanghai: Shanghai Translation Publishing House.

Hu, F., \& Gong, C. Y. (2008). The construction of schools with characteristics: The choice and construction of the school culture. Journal of the Chinese Society of Education, 4, 22-25.

Pang, P. (1993). Traditional culture and cultural tradition. Science and Chinese People, 4, 9-11.

Sun, G. F. (2012). Playing a positive transferring energy: Promoting knowledge internalization generating. Today’s Education, 12, 14.

The State Council of People's Republic of China. (2010). Planning outline of national long-term education reform and development (2010-2020, China). Retrieved from http://www.gov.cn/jrzg/2010-07/29/content_1667143.htm

Victor,E. (1988). The concept of culture. Shanghai: Shanghai People’s Publishing House.

Yang, J. J. (2013). The school construction with characteristics: “Searching for your own words”. Education Research, 10, 29-36.

Ye, L. (2006). The theory on new basic education-The investigation and cognition on the contemporary school reform in China. Beijing: Educational Science Publishing House.

Zhang, Q. (2008). The cultivation of school culture with personality shows the characteristics of running school. Journal of the Chinese Society of Education, 7, 31-34.

Zhong, Q. Q. (2003). Modern curriculum theory (New ed., pp. 462-463). Shanghai: Shanghai Education Press. 